\title{
Balancing study and paid work: the experiences of construction undergraduates in an Australian university
}

Helen Lingard (Ark Consulting Group Pty Ltd, Clifton Hill, Australia).

\begin{abstract}
A questionnaire survey was undertaken among third year students enrolled in the University of Melbourne's Bachelor of Property and Construction (BPC) programme. The survey explored students' experiences in balancing paid work with study. Hours spent in paid employment were at least as long and, in many cases, were in excess of hours spent at university. While work was not perceived by students to pose a difficulty for attending lectures and tutorials, students indicated that their paid work made it difficult for them to engage in independent learning activities, such as using library resources or preparing for classes by reading beforehand. Two scales, previously used in other countries to measure students' burnout and engagement, were tested. Both scales were found to be valid and reliable in that the factorial structures found in previous studies were confirmed and acceptable internal consistency reliability coefficients were generated for each of the scales' component factors. This opens the way for more in-depth multivariate analysis to determine the linkages between work hours, work-study conflict and students' burnout or engagement with university life.
\end{abstract}

Keywords: paid work, work-study balance, burnout, engagement, well-being.

\section{INTRODUCTION}

\section{The work-university interface}

The Bachelor of Property and Construction (BPC) is offered by the Faculty of Architecture, Building and Planning at the University of Melbourne. Between 1994 and 2002, the University of Melbourne's BPC ranked eighth out of the twelve Australian tertiary "building" courses in terms of good teaching and students' overall satisfaction with the course, as assessed by the Graduate Careers Council of Australia's Course Experience Questionnaire (Love and Newell, 2004). The course structure involves three years of study, followed by a 12 month industry placement. Following this placement, students return to the University for a final year of study. The industry placement is greatly valued by staff and students who regard it as an important learning experience. Many students work part time for the company in which they undertook this practicum when they return to complete their final year of the BPC. In recent years, the extent to which BPC students work in paid employment during semester time has become a source of concern. In 2002, the average hours worked by third and final year students was 20.5 and 19.0 respectively compared to only 9.5 among first year students (Lingard et al., 2003). In some cases, students report working up to 39 hours each week during semester time. Anecdotal evidence from staff suggests that many students are missing lectures and tutorials because of work commitments. Concerns also centre on the students' disengagement from university life and the possible impact of excessive workloads on their stress and well-being. The extent and impact of students' participation in paid work during semester-time continues to interest higher education researchers. Despite the fact that the BPC students report working considerably long hours in industry-based jobs, little is known about the experiences of these students at the work-university interface. The current study sought to explore these experiences.

\section{Students in paid work}

In recent years, the cost of financing an education has increased to such an extent that combining work and study may be a necessity for many students (Lipke, 2000; Curtis and Lucas, 2001; Curtis and Williams, 2002). Curtis and Williams (2002) write of the "routinisation" of students combining paid work and study, suggesting that this is now the norm.

\section{Benefits of combining paid work and study}

Some research suggests that semester-time work can provide positive benefits to students. Lucas (1997) reports that many students derive enjoyment and satisfaction from their part-time work, which forms the basis for much of their social life. Other studies suggest that participation in paid work brings educational benefits. For example, Watts and Pickering (2000) suggest that skills learned at work are transferable and students who work are more employable due to their development of organisational and time management skills. Working students are also said to develop good inter-personal skills (Lucas and Lammont, 1998). When parttime work is related to students' vocational coursework, it may be particularly beneficial as an aid to academic knowledge and career prospects.

Possible adverse effects of combining paid work and study However, other writers suggest that semester-time work has a detrimental impact upon students and their study. For example, working long hours is reported to have a negative effect on the study of high school students in the US (Hansen and Jarvis, 2000). In a study by Sorensen and Winn (1993), undergraduate students attributed the negative impact of work on study to having less time available for study, tiredness and the need to miss lectures to attend work. In an unpublished study at Oxford Brookes University in the UK, it is reported that every year, more than 200 students in part time work gain a degree at least one class lower than they would get were they not in paid work (Lindsay and PatonSaltzberg, cited in Curtis and Williams, 2002).

It is not just educational outcomes that are affected by students' excessive workloads. Research suggests that imposing undue stress upon students can negatively impact upon their well-being. Research shows high levels of stress in university students (Abouserie, 1994; Felsten and Wilcox, 1992; Cotton et al., 2002). British research suggests that University students experience difficulty in balancing work and study and experience above average levels of stress as a result (Humphrey et al., 1998).

The potential for work-study conflict

The conflict between one's work role and other life roles is an important aspect of the relationship between work and non-work life. Much research and theory building has focused on the conflict 
between work and family. For example, Greenhaus and Beutell (1985, p.77) defined work-family conflict as "a form of interrole conflict in which the role pressures from the work and family domains are mutually incompatible in some respect". Time is a limited resource and time commitments to paid work reduce the time available to fulfill duties required of another role. In adult life, work and family are primary life domains and researchers have developed and tested various models of the antecedents (e.g. work hours, number of children etc.) and consequences (e.g. absenteeism, low job satisfaction) of work-family conflict. Markel and Frone (1998) suggest that that in adolescent life, work and education are likely to be primary life domains. They provide empirical evidence to indicate that the number of hours spent in paid employment each week is positively associated with conflict between work and education among adolescents and young adults.

\section{The potential for burnout}

Given the significant time demands and possible conflict between the role of student and that of employee, the issue of 'burnout' is a concern. The most widely accepted definition of burnout conceptualises the phenomenon as a syndrome of emotional exhaustion, cynicism and reduced personal accomplishment (Maslach et al., 1996). Burnout is predicted by long hours, subjective overload (the feeling of having too much to do in the time available) and the requirement to fulfil the demands of conflicting roles (Schaufeli and Enzmann, 1998). Research also suggests that burnout is more likely to occur among younger people than among those over 30 or 40 years of age and among highly educated compared to less educated people (Maslach et al., 2001). These findings suggest that university students, particularly those working part-time, could be a high-risk group for burnout. One study revealed that perceived stress predicted burnout among working college students in the US (Chang et al., 2000). Burnout is reported to be negatively correlated with academic performance (Schaufeli et al., 2002a) and a sense of emotional exhaustion has been linked to students' disengagement from university life (Schaufeli et al., 2002a).

The impact of the combined workload of paid work and study on students is a concern because students are critically important to the future of knowledge-based economies. Student burnout is likely to lead to under-achievement among the student cohort and may even result in withdrawal and loss of talent from the workforce.

The construction industry suffers from a poor image. Already, construction is dropping in career appeal and shortage of skills has been highlighted as an issue for the 21st century. In the 1999 edition of the Jobs Rated Almanac, civil engineering fell from 18th to 70th position in expressed job preference and 14 construction trades were rated in the bottom ranks (Francis and Lingard, 2002). The availability and perceived quality of employment alternatives is recognised to be a key factor in job commitment and turnover. Burnout is also associated with diminished organisational commitment and an intention to turnover. Therefore, if students are suffering exhaustion and burnout before they graduate, they may choose alternative career paths on graduation, which would be a loss to the industry and threaten its long term competitiveness.

\section{Student engagement}

Consistent with an emerging trend towards positive psychology, in recent years researchers have started to investigate the concept of engagement. Engagement is regarded as being the antithesis of burnout (Schaufeli et al., 2002b) and is characterised by energy, involvement and a sense of efficacy (Maslach and Leiter, 1997). Engagement has been measured among employees and students. Engaged students are said to experience an energetic and effective connection with their study and see themselves as being able to deal completely with the demands of their courses. As the antithesis to burnout, engagement is likely to enhance students' experiences of university life.

\section{The study objectives}

In 2003, a study was undertaken to investigate the experiences of students enrolled in the Bachelor of Property and Construction programme at the University of Melbourne, Australia. The objectives of this study were as follows:

- $\quad$ To investigate the extent to which students were engaged in paid work during semester;

- To investigate the extent to which students perceived there to be conflict between their paid work and their university commitments;

- To test the reliability and psychometric properties of burnout and engagement scales developed and used in student samples in other countries; and

- $\quad$ To assess the relationship between burnout and engagement dimensions in an Australian student sample.

\section{METHODS}

\section{The sample}

A questionnaire was administered to undergraduate students enrolled in the third year of the Bachelor of Property and Construction degree course. Questionnaires were distributed during a lecture in a compulsory subject for year three students. Students were asked to respond to the survey during the lecture and place completed, un-named questionnaires into a sealed box provided for this purpose. The questionnaire was administered four weeks prior to the end of semester when student attendance at lectures is generally high. However, the sampling method used was limited in the respect that only students' attending the lecture were invited to participate. This could introduce bias into the results as students whose workload is the greatest may not have been in attendance.

A total of 102 usable questionnaires were returned, representing a $93 \%$ response rate among students in attendance at the scheduled lecture at which questionnaires were distributed. While this sample would not be considered large, Tabachnick and Fidell (2001) suggest that, with respect to Principal Components Analysis (see below), a sample of between 100 and 200 is sufficient for most purposes.

\section{Questionnaire design}

The questionnaire comprised six sections as follows:

- Information about the students' course enrolment and residential status (e.g. living with parents, friends, in a University College, with a spouse/partner etc.);

- Students' participation in paid work, including hours, schedule requirements, nature of employing organisation and rate of pay;

- Students' participation and feelings about University life, including contact hours, hours spent on campus, feelings of burnout and engagement (see below);

- $\quad$ Students' experiences in balancing work and study, including perceived work-study conflict and perceptions of the relative ease/difficulty experienced in meeting University requirements; and

- Qualitative comments regarding the level of satisfaction/ dissatisfaction with university life and paid work.

Owing to the sensitivity of data being collected, students were not asked to provide detailed demographic information, such as 
gender and age, as it was believed this could compromise their anonymity (see ethics procedure below).

\section{Burnout and engagement measures}

Burnout was assessed with a modified version of the Maslach Burnout Inventory - General Survey (MBI-GS). Schaufeli et al. (2002a; 2002b) adapted the MBI-GS for use within student samples. For example, the item "I feel emotionally drained from my work [italics added]" was changed to "I feel emotionally drained by my study [italics added]". The MBI-Student Survey (MBI-SS) consists of 16 items that constitute three scales: exhaustion (5 items); cynicism (5 items); and efficacy (6 items). All items are scored on a 7-point frequency rating scale ranging from 0 (never) to 6 (every day). High scores on exhaustion and cynicism and low scores on efficacy are indicative of burnout.

Engagement was measured using the Utrecht Work Engagement Scale (UWES) developed by Schaufeli and Bakker (2003). For the large part, the development of the student version of the UWES (the UWES-S) has involved positively rephrasing MBI items and making them applicable to assessing engagement amongst student populations. The UWES-S comprises 14 items, constituting three subscales: vigour; dedication; and absorption. "Vigour" is assessed by five items, for example, "When I am studying I feel strong and vigorous." Individuals scoring high on vigour are charactersed as feeling energised and having stamina for study. Low scores on the vigour scale indicate less energy and stamina for study. "Dedication" is assessed by five items, for example "I am proud of my studies." Individuals scoring high on dedication identify with their study because it is experienced as meaningful, inspiring and challenging. Individuals who score low on dedication do not identify with their study, experiencing it as lacking in meaning and uninspiring. Finally, "absorption" is measured by four items, for example "When I study, time flies." Individuals scoring high on absorption usually feel happily engrossed or immersed in their study, indeed to the extent that they have difficulties detaching from it. Individuals scoring low on absorption do not feel engrossed or immersed in their study, nor do they have difficulty detaching from it. All items are scored on a 7-point frequency rating scale ranging from 0 (never) to 6 (every day).

\section{Ethics procedure}

The research was subject to approval under the University of Melbourne's ethics process for research involving human subjects. Accordingly, students were advised that participation was voluntary and that a failure to participate would not prejudice their treatment in the Faculty. Students were also advised that participation was in no way linked to the assessment of any of their university work. The students were advised that returning the questionnaire indicated their willingness to participate in the survey and that data would be stored in a locked, secure location and be treated with strict confidentiality. Students were also provided with the option of placing completed questionnaires in a sealed box in the Faculty's Student Services office, if they preferred.

\section{Data analysis procedures}

Firstly, descriptive statistics were calculated for hours spent at work and at university. These descriptive statistics were tabulated. Descriptive statistics were also tabulated for the work-study conflict items. Secondly, given that the MBI-SS and UWES-S are both relatively new psychometric measures, a principal components analysis (PCA) was performed in order to examine their factorial structures and compare these to the factor structures hypothesised by Schaufeli and Bakker (2003). Lastly, to determine the relationship between the engagement and burnout factors in the present sample, a bi-variate correlation table was generated. The statistical software package SPSS was used to conduct these procedures.

\section{RESULTS}

\section{Students' circumstances}

Forty respondents (38.5\%) were enrolled in the Building Construction Management course stream. Nineteen respondents $(18.3 \%)$ were enrolled in the Building Economics/Quantity Surveying stream and 16 respondents (15.4\%) were enrolled in the Property stream. A further 22 respondents (21.2\%) were enrolled in the combined Bachelor of Property and Construction/ Bachelor of Architecture degree offered by the Faculty. A further four respondents (3.9\%) did not indicate which course/stream they were enrolled in.

The largest proportion of respondents ( $n=45,43.3 \%$ ) indicated they lived with their parents. Another 35 respondents (33.7\%) indicated they lived with friends in a flat or house-share arrangement. Seven students (6.7\%) reported living with a spouse/partner and two (1.9\%) reported living with a spouse/ partner and dependent child(ren). Eight students (7.7\%) reported living alone, one of whom also lived with a dependent child. Only two students $(1.9 \%)$ reported living in a University College. The remaining two students $(1.9 \%)$ did not indicate where or with whom they lived.

\section{Hours in paid employment}

Table 1 shows the least and most number of hours students reported working in paid work in any week during the month prior to the survey. The least hours worked ranged from 0 to 37 hours (SD 8 hours) and the most hours worked ranged from 10 to 55 hours (SD 10 hours). The mean least number of hours worked was 11.12 hours and the median was 10 . The mean most number of hours worked was 23.65 hours and the median was 20.

\begin{tabular}{lcccccc}
\hline & $\mathrm{N}$ & Minimum & Maximum & Median & Mean & Std. Deviation \\
\hline $\begin{array}{l}\text { Least number of hours worked in any week } \\
\text { during last month }\end{array}$ & 78 & 0.00 & 37.00 & 10 & 11.12 & 7.99 \\
$\begin{array}{l}\text { Most number of hours worked in any week } \\
\text { during last month }\end{array}$ & 78 & 10.00 & 55.00 & 20 & 23.65 & 10.00 \\
\hline
\end{tabular}

NB: $\mathrm{N}=78$ due to missing data

Table 1: Least and most number of hours worked in any week during the last month 
Table 2 shows the least and most number of hours worked by type of work. The results suggest that students working in quantity surveyors' offices and students working for property developers report working the greatest number of hours.

\begin{tabular}{|c|c|c|c|c|c|c|c|c|c|}
\hline \multirow[b]{2}{*}{ Type of work } & \multirow[b]{2}{*}{$\mathrm{N}$} & \multicolumn{4}{|c|}{ Least number of hours worked } & \multicolumn{4}{|c|}{ Most number of hours worked } \\
\hline & & Min. & Max. & Mean & SD & Min. & Max. & Mean & SD \\
\hline Casual & 37 & 0.00 & 21.50 & 8.69 & 6.61 & 10.00 & 50.00 & 20.88 & 8.39 \\
\hline Contractor & 11 & 0.00 & 20.00 & 10.45 & 6.04 & 14.00 & 40.00 & 24.20 & 8.73 \\
\hline Working in an architect's office & 14 & 0.00 & 20.00 & 10.62 & 4.79 & 12.00 & 50.00 & 22.85 & 10.56 \\
\hline $\begin{array}{l}\text { Working in a quantity surveyor's } \\
\text { office }\end{array}$ & 5 & 7.50 & 30.00 & 19.70 & 8.61 & 15.00 & 55.00 & 33.20 & 15.79 \\
\hline Working for a property developer & 8 & 8.00 & 37.00 & 20.00 & 11.60 & 15.00 & 50.00 & 26.00 & 12.37 \\
\hline $\begin{array}{l}\text { Casual work and working for a } \\
\text { contractor }\end{array}$ & 2 & 10.00 & 12.00 & 11.00 & 1.41 & 25.00 & 30.00 & 27.50 & 3.54 \\
\hline $\begin{array}{l}\text { Working for a contractor, a } \\
\text { property developer and another } \\
\text { employer }\end{array}$ & 2 & 0.00 & 6.00 & 3.00 & 4.24 & 20.00 & 30.00 & 25.00 & 7.07 \\
\hline $\begin{array}{l}\text { Casual work and working in an } \\
\text { architect's office }\end{array}$ & 2 & 3.00 & 26.00 & 14.50 & 16.26 & 12.00 & 35.00 & 23.50 & 16.26 \\
\hline All of the above & 1 & 18.00 & 18.00 & 18.00 & . & 34.00 & 34.00 & 34.00 & . \\
\hline $\begin{array}{l}\text { Unspecified other type of } \\
\text { employment }\end{array}$ & 2 & 0.00 & 16.00 & 8.00 & 11.31 & 24.00 & 38.00 & 31.00 & 9.90 \\
\hline
\end{tabular}

Table 2: Least and most number of hours worked in any week during the last month by type of work

Table 2 shows the least and most number of hours worked by type of work. The results suggest that students working in quantity surveyors' offices and students working for property developers report working the greatest number of hours.

Hours spent at University

Table 3 shows the number of hours students indicate that they spend at university in a normal week. In relation to course contact hours, students reported spending a minimum of 1 and a maximum of 36 hours at university in a normal week. The mean number of hours spent in course contact was 13.40 hours (SD 4.28 hours) and the median was 13 hours. In relation to using the university facilities for recreational purposes, students reported spending a minimum of 0 and a maximum of 25 hours at the university a week.

\begin{tabular}{lcccccc}
\hline & N & Minimum & Maximum & Median & Mean & $\begin{array}{c}\text { Std. } \\
\text { Deviation }\end{array}$ \\
\hline Course contact hours & 102 & 1.00 & 36.00 & 13 & 13.40 & 4.28 \\
Recreational activities & 100 & 0.00 & 25.00 & 4 & 6.95 & 6.70 \\
No of days per week spent on campus & 102 & 0.00 & 7.00 & 4 & 4.08 & 1.19 \\
\hline
\end{tabular}

Table 3: Average time spent per week at University

The mean number of hours using the campus for recreational purposes was 6.95 (SD 6.7 hours) and the median was 4 hours. The mean number of days students indicated they attended university was 4.08 (SD 1.19 days) and the median was 4 days.

Perceived work-study conflict

Table 4 shows students' perceptions that their work makes it difficult to meet university commitments. Students generally perceive that they are able to attend lectures and tutorials, meet with other students to engage in study-related activities, complete assignments before the due date and use internet study resources. However, students rate finding time to perform readings prior to class and preparation for lectures and tutorials and spending time using library resources "difficult." This suggests that students' paid work participation makes it difficult for them to engage in independent research-based activities relating to their study. 


\begin{tabular}{lccc}
\hline Item & N & Mean & SD \\
\hline To attend lectures and tutorials. & 72 & 2.35 & 1.01 \\
To attend meetings with other students. & 72 & 2.85 & 1.03 \\
To do readings before a class. & 72 & 3.75 & 0.95 \\
To prepare for lectures and tutorials. & 72 & 3.60 & 0.94 \\
To complete assignments before the due date. & 72 & 2.71 & 0.94 \\
To spend time using library resources. & 72 & 3.28 & 1.02 \\
To spend time using internet study resources. & 72 & 2.61 & 1.03 \\
\hline
\end{tabular}

NB: $N=72$ due to missing data

Perception of ease/difficulty to undertake each of the activities during semester time rated from $1=$ very easy to $5=$ very difficult.

Table 4: Perceived work-study conflict

Factorial structure of the burnout and engagement scales Prior to performing the PCA, the frequency distributions of the $\mathrm{MBI}$-SS were checked for normality and multivariate outliers were removed. The PCA yielded four components with eigenvalues larger than 1 , explaining $62 \%$ of the total variance. Both four and three components solutions were submitted to varimax rotation, however, the three component solution provided the less complex solution. The varimax rotated components are consistent with the underlying factor structure suggested by Schaufeli et al. (2002a; $2002 b)$. Further convergent evidence regarding the underlying factor structure is indicated by Cronbach's alpha coefficients, which were $.76, .78$ and .78 for the exhaustion, cynicism, and efficacy scales respectively. This indicates that the burnout scales have satisfactory internal consistency reliability in the Australian student sample.

The same procedure was followed to examine the factorial structure of the UWES-S scale. The PCA yielded two components with eigenvalues larger than 1, explaining $62.6 \%$ of the total variance. The first component explained $53 \%$ of the total variance, while the second component only explained $9.3 \%$. Two solutions were submitted to varimax rotation, the two component solution suggested by the current analysis, and the three component solution suggested by Schaufeli et al. (2002a; 2002b). Both the two and three component solutions proved complex. However, after careful analysis of the content of the components it was determined that the three component solution suggested by Schaufeli et al. (2002a; 2002b) provided a clearer theoretical explanation of the data than the two component solution. However, as noted previously, the results were complex, indicating a high degree of overlap between components. This may be an artifact of the smaller sample size of the current study compared with the larger sample sizes of Schaufeli et al. (2002a; 2002b), or that fact that the UWES-S has yet to be sufficiently normed against Australian samples. Despite the complexity of the components, each had high Cronbach alpha coefficients. These were .92, .92 and .87 for vigour, absorption, and dedication respectively, indicating acceptable internal consistency reliability in the Australian student sample.

The relationship between burnout and engagement factors Table 5 provides information concerning the relationship between the burnout and engagement scales employed in the current sample. Data relevant to the current study has been extracted from Schaufeli et al. (2002a) to provide cross cultural comparisons.

\begin{tabular}{|c|c|c|c|c|c|c|c|c|c|c|c|c|}
\hline & \multicolumn{3}{|c|}{ Spain $(n=621)$} & \multicolumn{3}{|c|}{ Portugal $(n=723)$} & \multicolumn{3}{|c|}{ Netherlands $(n=309$ ) } & \multicolumn{3}{|c|}{ Australia (n=102) } \\
\hline & $\mathrm{VI}$ & $\mathrm{DE}$ & $A B$ & VI & $\mathrm{DE}$ & $A B$ & VI & $\mathrm{DE}$ & $A B$ & VI & $\mathrm{DE}$ & $A B$ \\
\hline EX & $-.23^{*}$ & $-.17^{*}$ & $-.12^{*}$ & $-.30^{*}$ & $-.27^{*}$ & $-.10^{*}$ & $-.20^{*}$ & -.08 & .03 & $-.29^{*}$ & $-.28^{*}$ & $-.26^{*}$ \\
\hline $\mathrm{CY}$ & $-.38^{*}$ & $-.61^{*}$ & $-.32^{*}$ & $-.41^{*}$ & $-.67^{*}$ & $-.25^{*}$ & $-.43^{*}$ & $-.61^{*}$ & $-.30^{*}$ & -.19 & $-.34^{*}$ & -.15 \\
\hline PE & $-.69^{*}$ & $-.67^{*}$ & $-.56^{*}$ & $-.63^{*}$ & $-.59^{*}$ & $-.48^{*}$ & $-.65^{*}$ & $-.60^{*}$ & $-.50^{*}$ & $-.51^{*}$ & $-.64^{*}$ & $-.43^{*}$ \\
\hline
\end{tabular}

Note: VI=Vigour, $D E=$ Dedication, $A B=A b s o r p t i o n, E X=E x h a u s t i o n, C Y=C y n i c i s m$, and PE=Efficacy

* Correlation is significant at the 0.05 level or greater (2-tailed)

Table 5: Correlations between Maslach Burnout Inventory-Student Survey (MBI-SS) and Utrecht Work Engagement Scale-Student (UWES-S) (adapted from Schaufeli et al., 2002a, p.473)

Schaufeli has argued that because student burnout is considered to be an erosion of academic engagement it is expected that all burnout and engagement scales are at least moderately negatively related. According to Schaufeli et al. (2002a), a relatively strong association is particularly expected between exhaustion and vigour as well as between cynicism and dedication because these scales are antithetical.

The results of the Australian study are largely consistent with those reported by Schaufeli et al. (2002a). With the exceptions of vigour 
$(\mathrm{VI})$ and cynicism (CY), and absorption (AB) and cynicism (CY) in the present study, the remaining correlations are significantly and negatively correlated. The current results replicate the trend in the other three samples in that correlations are highest, that is modestly negatively correlated, between personal efficacy $(\mathrm{PE})$ and the three engagement scales. Interestingly, it should be noted that the expected relationships between exhaustion and vigour and cynicism and dedication are not as strong as might be expected on theoretical grounds. As can be seen from Table 5, this finding is also apparent in the other samples.

\section{DISCUSSION}

The results suggest that students in the BPC programme spend a large number of hours in paid employment. On average, hours spent in paid employment equal or exceed those spent at the university.

The impact of students' commitments to paid work on well-being and educational outcomes should now be evaluated. While participation in paid work can undoubtedly yield educational and personal benefits, the possibility that students are "overworked" exists. Some studies suggest that students who work up to ten and fifteen hours per week benefit from this but that working longer hours than this can have a deleterious impact on students' well-being and performance (Curtis and Lucas, 2001). If this is the case, many students in the BPC programme are working hours in excess of the desirable limit. The results of this study suggest that BPC students are able to attend lectures and tutorials but that their paid work makes it difficult for them to engage in independent study or research, potentially posing a problem for existing models of teaching and learning.

From an educational perspective, there is some debate as to whether the quality of education should be judged according to the breadth and width of the problems that education poses for students (Lomas, 1997) or by the market model, in which excellence is displayed when the product (the graduate) sells well (McMurtry, 1991). If the former perspective is taken, then it is possible that the breadth, as well as the depth, of education will suffer where the student attends lectures but is unable to undertake any independent research-based study. However, the fact that BPC students are employed so extensively in industrybased jobs indicates that the construction industry recognises their "value." Despite the employability of BPC students, the motivation of construction industry employers in providing students with "work experience" may also be questioned. Curtis and Lucas (2001) suggest that students represent a source of "cheap labour" for some employers, who may not always have the students' best interests in mind. For example, Taylor (1998) found that, although students may initially be contracted to undertake work hours that do not conflict with university commitments, often employers subsequently place students under pressure to work hours that do interfere with their study. Such behaviour is short-sighted and may pose a further threat to students' well-being.

The MBI-SS and UWES-S have now been tested in an Australian student population and the validity and reliability of both measures have been demonstrated. It is now imperative that further research be conducted to examine the extent to which students' involvement in paid work impacts directly upon their burnout and engagement with university life and impacts indirectly upon their educational outcomes. The results of this future research would identify the extent to which students suffer as a result of over-work arising as a result of combining paid work with study.
Australian universities need to recognise that paid work is a reality for students and that involvement in paid work is unlikely to recede due to the economic factors impacting upon the cost of undertaking higher education. However, greater cooperation between universities and industry may be needed in the future to better protect students of the built environment sciences from any ill-effects arising as a result of overwork and to ensure that educational outcomes are not sacrificed. This may involve the development of work-based learning models by which the educational benefits derived from students' part-time work are monitored and assessed and linkages between theory (learned at university) and industry practice are made explicit.

\section{CONCLUSIONS}

At present, little is known about construction students experiences at the interface between university and paid work. The results of this study suggest that students enrolled in the BPC degree course in one Australian university engage in paid work to at least the same extent as they spend in university activities and that, as a result of paid work, they find it difficult to engage in independent or research-based learning activities. It is possible that the extensive hours spent in paid employment result in burnout and a disengagement from university life. Previously used measures of student burnout and engagement were tested in this study and found to be valid and reliable in the Australian student sample. This being the case, research is now focused on testing a multivariate model and assessing the linkages between work hours, work-study conflict and student burnout and engagement.

In this study academic outcomes were not evaluated because the questionnaire was completed anonymously. Future studies should also investigate the impact of the combined workload of paid work and university study on work-study conflict, burnout/ engagement and academic outcomes.

\section{REFERENCES}

Abouserie, R. (1994), 'Sources and levels of stress in relation to locus of control and self esteem in university students', Educational Psychology, pp.323-330.

Chang, E. C., Rand, K. L. and Strunk, D. R. (2000), 'Optimism and risk for job burnout among working college students: stress as a mediatior', Personality and Individual Differences, vol.29, pp.255-263.

Cotton, S. J., Dollard, M. F., de Jonge, J. (2002), 'Stress and student job design: Satisfaction, well-being and performance in university students', International Journal of Stress Management, vol.9, pp.147-161.

Curtis, S. and Lucas, R. (2001), 'A coincidence of needs: employers and full-time students', Employee Relations, vol.23, pp.38-54.

Curtis, S. and Williams, J. (2002), 'The reluctant workforce: undergraduates' part-time employment', Education and Training, vol.44, pp.5-10.

Felsten, G. and Wilcox, K. (1992), 'Influences of stress and situation-specific mastery beliefs and satisfaction with social support on well-being and academic performance', Psychological Reports, vol.70, pp.291-303. 
Francis V.E. and Lingard H. (2001), "Work - life" employment practices - meeting the needs of construction professionals in the 21st century', in proceedings of the Australasian University Building Educators Association 26th Annual Conference, Constructing and Managing the Built Environment: Education and Research for the Future, Adelaide, 11-13 July, pp.121-129.

Greenhaus, J. H. and Beutell, N. J. (1985), 'Sources of conflict between work and family roles', Academy of Management Review, vol.10, pp.76-88.

Hansen, D. M. and Jarvis, P. A. (2000), 'Adolescent employment and psychological outcomes', Youth and Society, vol.31, pp.417436.

Humphrey, R., McCarthy, P., Popham, F, Charles, Z., Garland, M., Gooch, S., Hornsby, C.H. and Muldoon, C. (1998), 'Stress and the contemporary student', Higher Education Quarterly, vol.52, pp.221-242.

Lingard, H., Mills , A. and Ashford, P., (2003), 'Patterns of semester-time employment among undergraduate Property and Construction students: a preliminary investigation' , in proceedings of the Australasian University Building Educators Association 26th Annual conference, Deakin University, Geelong, July 2003.

Lipke, D.J. (2000), 'Work study', American Demographics, vol.22, pp.9-14.

Lomas, L. (1997), 'The decline of liberal education and the emergence of a new model of education and training', Education and Training, vol.39, pp.111-115.

Love, P. and Newell, G. (2004), 'Good teaching and overall satisfaction in Australian university building education' in proceedings of the Australasian University Building Educators Association 29th Annual Conference, University of Newcastle, New South Wales, July 2004

Lucas, R. (1997), 'Youth, gender and part time work: students in the labour process', Work, Employment and Society, vol.11, pp.595-614.

Lucas, R. and Lammont, N. (1998), 'Combining work and study: an empirical study of full-time students in school, college and University', Journal of Education and Work, vol.11, pp.41-56.

Markel, K.S. and Frone, M.R. (1998), 'Job characteristics, workschool conflict and school outcomes among adolescents: Testing a structural model', Journal of Applied Psychology, vol.83, pp.277287.

Maslach, C. and Leiter, M.P. (1997), The truth about burnout, Jossey Bass, San Francisco, CA.

Maslach, C., Jackson, S.E. and Leiter, M.P. (1996), Maslach Burnout Inventory Manual, Palo Alto, CA: Consulting Psychologists Press, 3rd Edition.

Maslach, C., Schaufeli, W.B. and Leiter, M.P. (2001), 'Job burnout', Annual Review of Psychology, vol.52, pp.397-422.

McMurtry, J. (1991), 'Education and the market model', Journal of the Philosophy of Education, vol.25, pp.209-217.
Schaufeli, W. and Enzmann, D. (1998). The burnout companion to study and practice: a critical analysis, London: Philadelphia, PA, Taylor \& Francis.

Schaufeli, W.B., Martinez, I.M., Marques Pinto, A., Salanova, M. and Bakker, A.B. (2002a), 'Burnout and engagement in university students: A cross-national study', Journal of Cross-Cultural Psychology, vol.33, pp.464-481.

Schaufeli, W.B., Salanove, M., Gonzalez-Roma, V. and Bakker, A. (2002b), 'The measurement of engagement and burnout: a two sample confirmatory factor analytic approach, Journal of Happiness Studies, vol.3, pp.71-92.

Schaufeli W. and Bakker, A. (2003), Utrecht Work Engagement Scale, Preliminary Manual, Version 1, November 2003, Occupational Health Psychology Unit, Utrecht University.

Sorensen, L. and Winn, S. (1993), 'Student loans: a case study', Higher Education Review, vol.25, pp.48-65.

Tabachnick, B.G. and Fidell, L.S. (2001), Using Multivariate Statistics, (4th edition), Allyn and Bacon, Boston, MA.

Taylor, N. K. (1998), 'Survey of paid employment undertaken by full-time undergraduates at an established Scottish University', Journal of Further and Higher Education, vol.22, pp.33-40.

Watts, C. and Pickering, A. (2000), 'Pay as you learn: student employment and academic progress', Education and Training, vol.42, pp.129-134. 